\title{
CARACTERIZAÇÃo MORFológiCA do FRUto, SEMENTE, PlÂNTUla E Planta JOVEM E GERMINAÇÃO DE Inga ingoides (Rich) Willd
}

\author{
Maria do Socorro Souto Braz 1 , Suzana de Lourdes Sousa Freitas², Maria Auxiliadora Leal Campos³, \\ Diêgo Dourado Oliveira Amazonas de Miranda ${ }^{4}$, Michelle Cavalcanti Cosme ${ }^{4}$
}

(recebido: 13 de julho de 2010; aceito: 28 de fevereiro de 2012)

\begin{abstract}
RESUMO: Nesta pesquisa, objetivou-se descrever e ilustrar as características morfológicas do fruto, semente, plântula e planta jovem e germinação da espécie Inga ingoides (Rich) Willd. Utilizaram-se 100 frutos para a descrição morfológica externa, no qual observou-se: tipo, forma, comprimento, superfície, cor, deiscência, tipo de pericarpo e número de sementes por frutos. Para o estudo das características morfológicas das sementes, foram utilizadas 100 amostras, observando: forma, comprimento, superfície da testa, cor e tipo de cotilédones, posição e descrição do embrião (tipo, forma do eixo hipocotiledonar). A descrição das características morfológicas da fase de germinação foi realizada em ambiente controlado (condições de laboratório) a uma temperatura ambiente de $28^{\circ} \mathrm{C}$ e $70 \%$ umidade relativa do ar, quando acompanhou-se até o surgimento dos primeiros metáfilos, com posterior descarte. A fase de planta jovem foi analisada durante um período de 28 dias em condições de casa de vegetação, observando-se as seguintes características: tipo de emergência, tipo de raiz, hipocótilo, cotilédones, epicótilo e tipo de metáfilo. Diante dos resultados, constatouse que os frutos de Inga ingoides (Rich) Willd. são do tipo legume, subtipo legume nucóide, apresentando de 4 à 18 sementes. As sementes possuem forma obvada, variando para oblonga com presença de sarcotesta, com germinação do tipo semi-hipógea. Nas plântulas e plantas jovens observou-se a presença de metáfilos bifoliolados, com pecíolo alado, textura coriácea, coloração verdeescura na face superior (adaxial) e verde-clara na inferior (abaxial) com estípulas.
\end{abstract}

Palavras-chave: Sementes florestais, leguminosas, morfologia.

\section{MORPHOLOGICAL CHARACTERIZATION OF FRUITS, SEEDS, SEEDLINGS AND SAPLINGS AND GERMINATION OF Inga ingoide (Rich) Willd}

\begin{abstract}
The aim of this research was to describe and illustrate the morphological characters of the fruits, seeds, seedling, sapling and phase of germination of Inga ingoides (Rich) Willd. For the description of the external morphological aspect 100 fruits were used and the following measurements were observed: type, shape, length, surface, color, dehiscence, pericarp type and number of seeds per fruit. The study of the morphological characteristics of the seeds used 100 seeds in order to observe the: shape, length, surface of the testa, color and cotyledons type, position and the embryo description (type and the form of the hypocotyls axis). The analysis of the morphological characterization of the germination phase was performed in a controlled environment (laboratory conditions), 280 C ambient temperature and relative humidity of 70\%, that was followed until the appearance of the first metaphylls, after that it was discarded. The sapling phase it was observed during a period of 28 days in ideal greenhouse conditions and the following measurements were observed: emergency type,root type, hypocotyls type, cotyledons, epicotyls and metaphylls type. Considering the results, were observed that the fruits of Inga ingoides (Rich) Willd, are a legume type, nucoide legume subtype presenting 4 to 18 seeds. The shape of the seeds varies between obvate to oblong with the presence of sarcotesta and semihypogeal germination. The seedling and sapling presents compounds methaphylls with winged petiole, coriaceous texture, dark green upper surface (adaxial), light green lower surface (abaxial) with stipule.
\end{abstract}

Key words: Forest seeds, leguminosas, morphology.

\section{INTRODUÇÃO}

Atualmente, a divisão da família Leguminosae em três famílias ou subfamílias distintas, tem sido alvo de divergências entre os diferentes autores. Souza e Lorenzi (2005) afirmam que tradicionalmente a família foi reconhecida como uma única família, com três subfamílias (Mimosoideae, Caesalpinoideae e Papilionoideae ou Faboideae). Já, Cronquist (1988) e outros autores preferiram reconhecer três famílias distintas

\footnotetext{
${ }^{1}$ Bióloga, Professora Doutora em Agronomia - Universidade de Pernambuco - Campus Nazaré da Mata-FFPNM - Departamento de Biologia Cx. P. 55 - 800-000 - Nazaré da Mata, PE, Brasil - mssbraz@hotmail.com

${ }^{2}$ Bióloga, Professora da Rede Estadual de Pernambuco - Cx. P. 55 - 800-000 - Nazaré da Mata, PE, Brasil - suzana_lourdes@yahoo.com.br

${ }^{3}$ Bióloga, Professora Mestra em Botânica - Universidade de Pernambuco - Campus Nazaré da Mata-FFPNM - Departamento de Biologia Cx. P. 55-800-000 - Nazaré da Mata, PE, Brasil - macampos@hotlink.com.br

${ }^{4}$ Biólogo, Pós-graduando em Microbiologia - Universidade de Pernambuco - Campus Nazaré da Mata-FFPNM - Departamento de Biologia Cx. P. 55 -800-000 - Nazaré da Mata, PE, Brasil-diegoamaz0nas@hotmail.com, chellycavlanti@hotmail.com
}

Cerne, Lavras, v. 18, n. 3, p. 353-360, jul./set. 2012 
(Caesalpiniaceae, Mimosaceae e Fabaceae). A família Fabaceae destaca-se não só no ponto de vista econômico, como alimentar - dada a importância na alimentação dos seres humanos (ex. feijão, soja), como também pode ser utilizada na adubação verde, entre outras tantas utilidades. A espécie Inga ingoides (Rich) Willd., popularmente conhecida como Ingá, de acordo com a classificação de Cronquist (1988) pertence a família Leguminosae, subfamília Mimosoideae, tribo Ingeae. Segundo Bethan (1876), Joly (2002), Mata (2009) e Pennington (1997) afirmam que esse gênero caracteriza-se por: apresentar porte arbóreo com folhas sempre de disposição alternas, paripenadas (raras na subfamilia) com presença de estípulas, e raquis alada com presença de nectário entre os folíolos - sendo o fruto do tipo legume característico da espécie - e apresenta sementes envoltas em mucilagem ou polpa doce. A referida espécie pertence a um gênero exclusivo neotropical, onde o litoral e interior brasileiro se encaixam como uma das principais áreas fitogeográficas para sua distribuição (PENNINGTON, 1997). É uma espécie de grande importância na recuperação de matas degradadas, sombreamento para agricultura, fonte de alimento, na produção de energia, na estabilização de solos ácidos e na fitoterapia (BILIA, 2003).

Estudos sobre a morfologia de sementes, descrições das fases iniciais da germinação e a morfologia de plântula nos estágios iniciais de desenvolvimentos, subsidiam em: testes de germinação em laboratório, na produção de mudas no viveiro, na área da silvicultura, no estabelecimento da dinâmica de populações, além de ser também fundamental para uma melhor compreensão do processo de estabelecimento da planta em condições naturais na floresta (COELHO et al., 2001; DAVIDE et al., 2000; GUERRA et al., 2006). O gênero Inga Miller é bastante pesquisado quanto sua taxonomia, entretanto, pesquisas abordando descrições morfológicas de frutos, sementes, plântula e planta jovem e fases da germinação são quase que inexistentes.

Diante do exposto, nesta pesquisa, objetivou-se descrever, caracterizar e ilustrar a morfologia do fruto, semente, plântula, planta jovem e da fase da germinação da espécie Inga ingoides (Rich) Willd. visando com isto, a fornecer subsídios que irão auxiliar não só no reconhecimento da mesma no campo, como também auxiliar em estudos de fisiologia, taxonomia, morfologia, tecnologia de sementes, ações ambientais de preservação e recuperação de áreas florestais que envolvam essa espécie.

Cerne, Lavras, v. 18, n. 3, p. 353-360, jul./set. 2012

\section{MATERIAL E MÉTODOS}

O experimento foi conduzido no Laboratório de Biologia e casa de vegetação da Universidade de Pernambuco, Campus Nazaré da Mata, Nazaré-PE. Os frutos da espécie estudada foram coletados no Sítio Camarazinho, no distrito de Tupaóca- Aliança- PE em um fragmento de Mata Atlântica. O sitio é uma propriedade particular com extensão de 2 ha (dois hectares), localizado na Zona da Mata Norte pernambucana. Os limites deste fragmento de mata são circundados por canaviais, uma estrada de terra, lavoura de subsistência e construções para moradia.

\subsection{Morfologia dos frutos}

Coletou-se os frutos diretamente da planta-mãe, livres de quaisquer danos físicos e biológicos, sendo, posteriormente, transportado para o Laboratório de Biologia da Universidade de Pernambuco, Campus Nazaré da Mata-PE, para beneficiamento e mensuração dos mesmos. Selecionaram-se 100 frutos, aleatoriamente, para verificar o tipo, forma, cor, dimensões (comprimento e largura), superfície, deiscência, pericarpo (seco ou carnoso), e número de sementes por frutos. As medições dos frutos foram realizadas com auxilio de régua graduada $\mathrm{em} \mathrm{cm}$ (centímetros). As descrições morfológicas dos frutos, foram feitas de acordo com a terminologia de Barroso et al. (1999).

\subsection{Morfologia das sementes}

As sementes foram retiradas manualmente dos frutos, em seguida, foram friccionadas em peneiras, lavadas em água corrente para a remoção da sua sarcotesta (mucilagens) (CARMONA et al., 1994). Após esse procedimento, as sementes foram mantidas à sombra por um período de três horas, para perda do excesso de umidade. Decorrido esse tempo, selecionaram-se, aleatoriamente, 100 sementes para a sua descrição morfológica, observando as seguintes características: forma, cor, dimensões (comprimento, largura), superfície da testa, presença ou ausência de pleurograma, tipo do hilo, funículo e ala, cotilédones (cor, consistência) e tipo de embrião. As medições das sementes foram realizadas com auxilio de régua graduada em $\mathrm{cm}$ (centímetros). As descrições da caracterização das sementes foram baseadas nos trabalhos de Barroso et al. (1999) e Beltrati (1994).

\subsection{Emergência das plântulas}

As observações das características das plântulas, foram realizadas no laboratório de biologia e casa de 
vegetação. Nos ensaios de germinação em condições de Laboratório, para observação das fases iniciais da germinação, utilizaram-se 100 sementes, semeadas em Placas de Petri, distribuídas em quatro repetições de 25 sementes, tendo como substrato papel de filtro, umedecido diariamente com $2 \mathrm{ml}$ de água destilada, mantidas a temperatura ambiente de $28^{\circ} \mathrm{C}$ e $70 \%$ umidade relativa do ar. As observações foram realizadas até o aparecimento dos primeiros metáfilos, com posterior descarte. Considerouse germinação, o período compreendido entre o período de intumescimento da semente até o surgimento da radícula (LABOURIAU, 1983). Paralelo aos ensaios de germinação em laboratório, instalaram-se os ensaios em condições de casa de vegetação onde a semeadura foi realizada em bandejas plásticas, contendo como substrato areia + terra + esterco curtido, proporção de $(2: 2: 1 / 2 \mathrm{v})$ na profundidade de $2,0 \mathrm{~cm}$, totalizando 100 sementes, distribuídas em quatro repetições de 25 sementes, observando-se, diariamente, durante o período de 28 dias, para a descrição morfológica das características da plântula e, planta jovem. Em condições de casa de vegetação, considerou-se germinada as plântulas que apresentaram os cotilédones sob o solo. Considerou-se o estágio de plântula, período compreendido entre o surgimento do primeiro e o segundo par de metáfilos, adotando-se a definição de Parra (1984). Foram consideradas plantas jovens, as planta aos 28 dias após semeio em condições de casa de vegetação com o aparecimento do terceiro par de metáfilos. As características observadas foram: tipo de emergência e plântula, tipo de raiz (coloração, presença de raízes secundárias e terciárias), tuberosidade (presença/ausência), nódulos (presença/ausência), hipocótilo (coloração e forma), cotilédones (forma, coloração, e textura), epicótilo (coloração e forma), tipo de folha - metáfilo (filotaxia, coloração, textura, base, margem e ápice). A terminologia empregada para a descrição dos caracteres externos das plântulas e plantas jovens baseou-se na classificação de Ducke $(1965,1969)$ e Ducke e Polhill (1981). Todas as características morfológicas descritas foram realizadas com auxílio de lupa binocular e uma maquina digital.

\section{RESULTADOS E DISCUSSÕES}

Os frutos de Inga ingoides (Rich) Willd são do tipo legume, subtipo legume nucóide, possuem o pericarpo seco, com reduzido teor de água na maturidade, indeiscente ou tardiamente deiscente, de formato linear, cilíndrico, meio curvados. É um tipo de fruto que possui muitas sementes, de coloração verde-claro, linear, rugoso $\mathrm{com} 7,0 \mathrm{~cm}$ à 23,1 $\mathrm{cm}$ de comprimento e $0,4 \mathrm{~cm}$ à $1,7 \mathrm{~cm}$ de largura com um número de 4 à 18 sementes por frutos (Figura 1). Em relação ao tipo de fruto descrito nesta pesquisa, constatou-se que as características observadas foram similares às observadas por Barroso et al. (1999), onde definem o legume como um fruto com pericarpo que pode ser seco ou mais raramente, carnoso com textura papirácea, coriácea ou lenhosas. Quando maduros, esse frutos expõem suas sementes abrindo as suas fendas longitudinais. Pennington (1997) afirma que os frutos de Inga ingoides (Rich) Willd. são reconhecidos pelo formato de seu fruto cilíndrico com linhas longitudinais expandidas, como constatou-se na referida espécie. Barroso et al. (1999) e Souza (2003) ressaltam que o legume é o tipo de fruto típico das espécies da família Fabaceae (Leguminosae), uma vez que, é o tipo de fruto mais encontrado nas três subfamílias das Leguminosae, ocorrendo uma grande diversidade morfológica, variando principalmente nas formas de deiscência, na configuração e ornamentação do pericarpo, na ausência ou presença de septos, como também no número de sementes. Segundo Barroso et al. (1999) e Bravato (1974), o tipo de fruto Legume apresenta formas bastantes variadas, essa diversificação do fruto pode ser uma consequência de adaptações especiais para dispersão de suas sementes. Dando prosseguimento às pesquisas com a família Fabaceae, Souza (2003), ao estudar o fruto de Inga fagifolia (ingá-mirim), constatou que essa espécie apresentou fruto do tipo legume indeiscente, embora possa apresentar eventualmente deiscência passiva, afirmando, com isso, que o legume é o fruto típico das espécies da Família Fabaceae (Leguminosae).

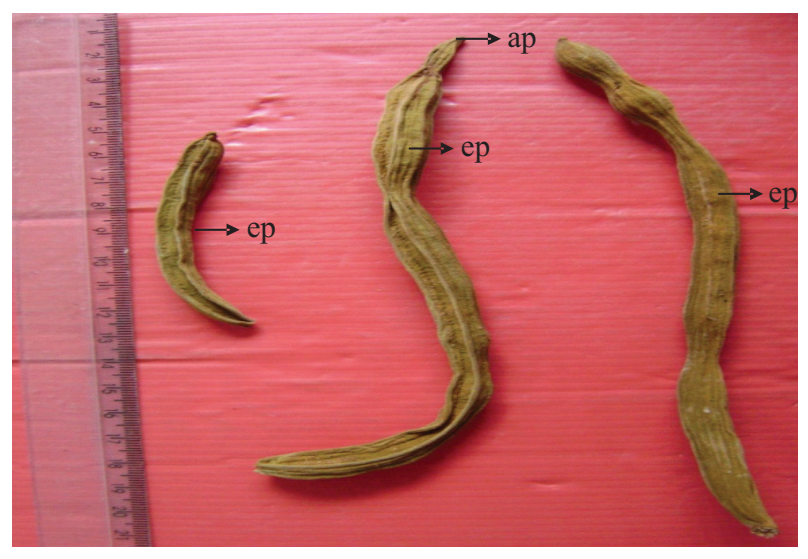

Figura 1 - Aspecto geral do fruto Inga ingoides (Rich) Willd vista frontal: ep - epicarpo; ap - ápice.

Figure 1 - General morpholgy of Inga ingoides Rich Willd fruit frontal view: ep-epicarp; ap- apex.

Cerne, Lavras, v. 18, n. 3, p. 353-360, jul./set. 2012 
As sementes de Inga ingoides possuem forma obvada, variando para oblonga, algumas com coloração verde escuro e outras verde mais claro, testa de textura delgada, superfície lisa e brilhosa, medindo $0,9 \mathrm{~cm}$ à $1,9 \mathrm{~cm}$ de comprimento por $0,5 \mathrm{~cm}$ à $1,3 \mathrm{~cm}$ de largura, as quais eram envolvidas por uma polpa adocicada de coloração esbranquiçada, denominada de sarcotesta (Figura 2). A presença da sarcotesta é característica das sementes de Inga. Resultados semelhantes foram constatados por Oliveira (1991), Oliveira e Beltrate (1992), Pennington (1997) e Poncy (1984), ao realizarem pesquisas com espécies do gênero Inga sp, Inga uruguensis Hooke e Arn. Fato também verificado por Barbedo e Bilia (1997), ao realizar testes de germinação de sementes e desenvolvimento de plântulas de Inga uruguensis Hooke e Arn. em função da remoção da sarcotesta, observaram que a presença dessa estrutura alterou os resultados do teste de germinação na referida semente (Figura 2).

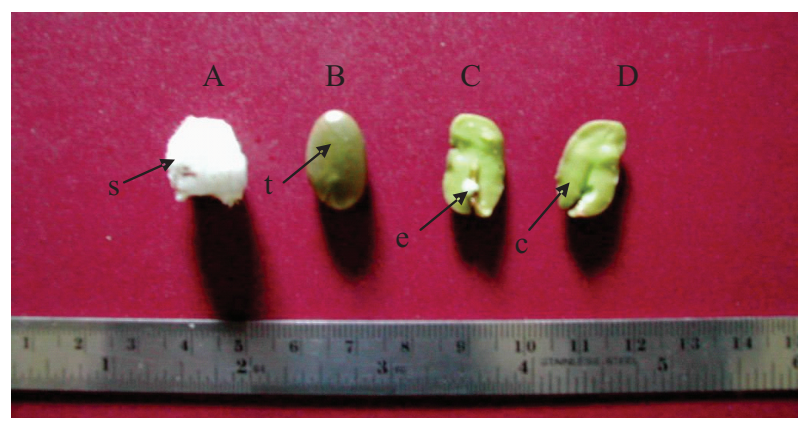

Figura 2 - Aspectos morfológicos da semente de Inga ingoides (Rich) Willd: A - semente com sarcotesta (s: sarcotesta); B semente sem sarcotesta ( $\mathrm{t}$ : tegumento); $\mathrm{C}$ - vista com corte longitudinal da semente (e: eixo embrionário); D - vista com corte logintudinal da semente (c: cotilédones)

Figure 2 - Morphology of Inga ingoides (Rich) Willd seed: A seed with sarcotesta (s:sarcotesta); $B$ - seed without sarcotesta ( $t$ : tegument); $C$ - longitudinal cross section view of the embryo axis (e :embryo axis); $D$ - longitudinal cross section view of the seed ( $c$ : cotyledons).

Quanto ao embrião a espécie Inga ingoide apresentou cotilédones plano-convexos, crassos, verdeescuros, dispostos paralelamente ao eixo hipocótiloradícula que é reto, curto com muita pilosidade e fica oculto na parte interna entre os cotilédones, com a plúmula rudimentar (Figura 3). As características observadas nessa espécie enquadraram-se naquela descritas por Barroso et al. (1999) e Oliveira e Beltrate (1992), ao estudarem a variedade Inga urugüaensis e I. uruguensis.

Cerne, Lavras, v. 18, n. 3, p. 353-360, jul./set. 2012

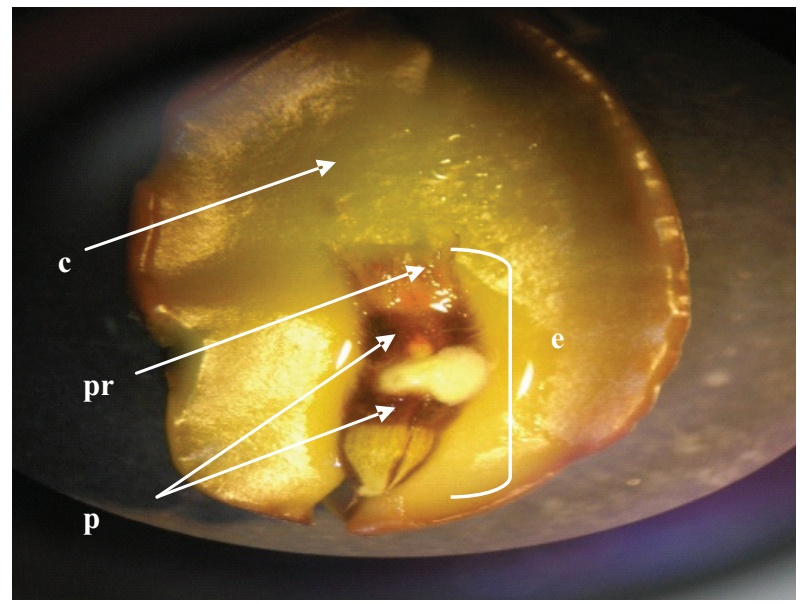

Figura 3 - Aspectos morfológicos do eixo embrionário de Inga ingoides (Rich) Willd.: vista com corte longitudinal da semente (e: eixo embrionário curto; c: cotilédones; pr: plúmula rudimentar, p: pilosidade)

Figure 3 - Morphology of Inga ingoides (Rich) Willd embryo axis: longitudinal cross section view of the seed (e: embryonic axis straight; $c$ : cotyledons; pr: rudimentar plumule; $p$ : pubescent).

Quanto à germinação da semente constatou-se que foi do tipo semi-hipógea, com raiz principal do tipo pivotante, de coloração branca, com presença de raízes secundárias curtas e finas, os cotilédones em número de dois são oblongos de coloração verde, crassos, textura carnosa (Figura 4). O epicótilo é verde-claro, com pêlos distribuídos em toda a sua extensão.

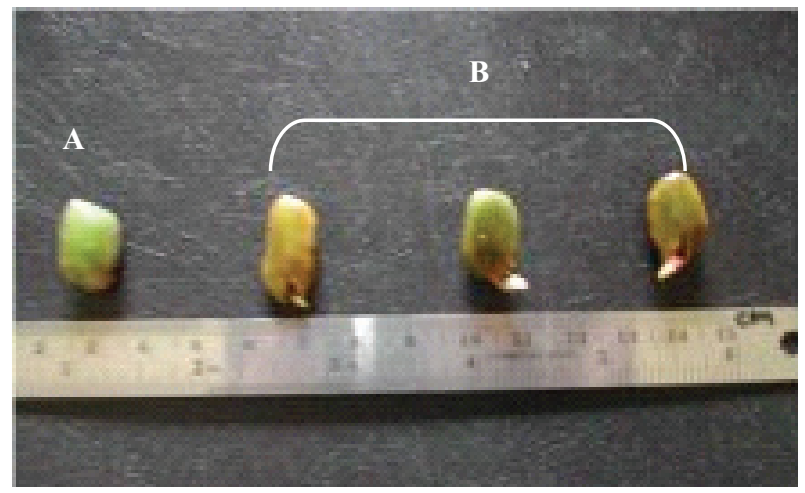

Figura 4 - Aspectos morfológicos da semente e da germinação de Inga ingoides (Rich) Willd.: A - vista frontal da semente; B - protusão da radícula.

Figure 4-Morphology of Inga ingoides (Rich) Willd germination and seeds : A -front view of seed; $B$ - protugion of radicule. 
Na germinação dessa espécie constatou-se que os cotilédones permanecem sob a superfície do solo, isto é, não ficando dentro do solo, e, em razão desse motivo, classificouse como germinação semi-hipógea, com posterior liberação dos cotilédones do tegumento, ficando livres. Duke (1965, 1969) classifica a germinação das sementes de Inga do tipo criptocotiledonar com cotilédones não fotossintéticos com pecíolo alados. Dando continuidade às pesquisas com a família das Leguminosae, Duke e Polhill (1981) ressaltam que na subfamilia Mimosoideae as plântulas são epígeas, porém há algumas espécies nas quais observa-se a plântula hipógea. Fato esse constatado por Oliveira e Beltrate (1992), ao estudarem a variedade Inga urugüaensis e I. uruguensis, classificando-as de germinação semi-hipógea.

Quanto á morfologia externa da plântula, constatouse a presença de dois pares de metáfilos bifoliolados, verdes claro, textura coriácea, nervura principal bem visível, seguida de quatro nervuras secundárias; margem lisa, ápice acuminado, base atenuada e pecíolo alado com presença de estípulas (Figura 5). Quanto à presença do pecíolo alado Barroso et al. (1991) e Souza (2003) afirmam que o pecíolo pode apresentar alas lateralmente, como em folhas de Inga. Observou-se, também, a presença de nectário extrafloral entre os folíolos dos metáfilos de Inga ingoides, sendo também características morfológicas da espécie de Inga ingoides (Figura 6).

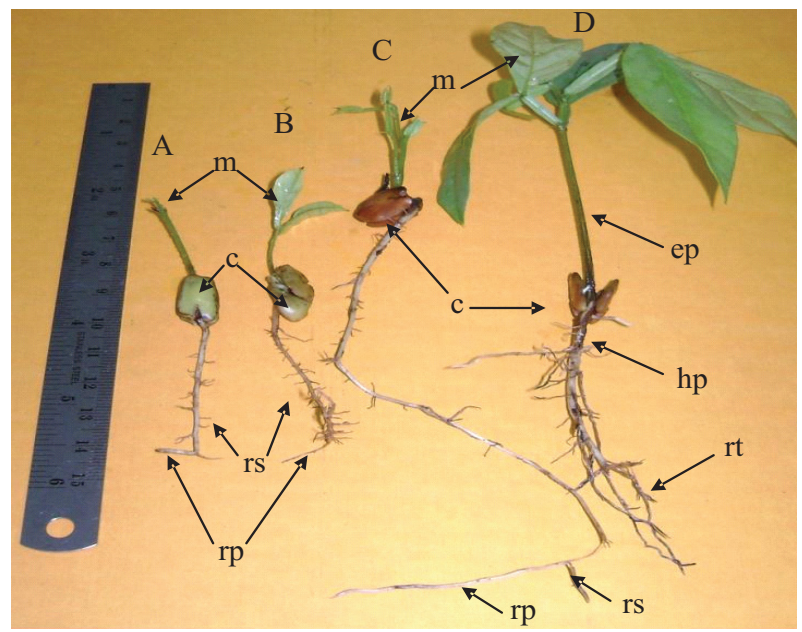

Figura 5 - Aspectos morfológicos da plântula e planta jovem da semente de Inga ingoides (Rich) Willd.: c - cotilédones, ep epicótilo, hp - hipocótilo, m - metáfilo, rp - raiz primária, rs - raíz secundária, $\mathrm{rt}$ - raiz terciaria.

Figure 5-Morphology of Inga ingoides (Rich) Willd seedling and sapling: c-cotyledons, ep - epicotyl, hp - hipocotyl, $m$ - metaphylls, $r p$ - primary roots, $r s$ - secondary roots, $r t$ - terciary roots.

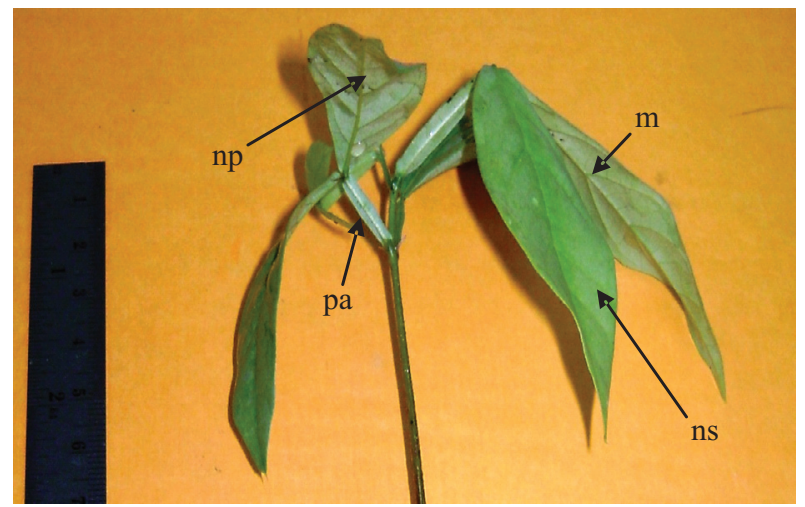

Figura 6 - Aspectos morfológicos do metáfilo de Inga ingoides (Rich) Willd.: m - metáfilo, pa - pecíolo alado, np - nervura principal, ns - nervuras secundárias.

Figure 6-Morphology of the metaphylls of Inga ingoides (Rich) Willd.: m-metaphylls, $p a$ - wings petiolar, $n p$ - principal veins, $n s$ - secondary veins.

Aos 28 dias, após o semeio em condições de casa de vegetação, as plantas jovens apresentaram raiz principal pivotante de coloração creme, raízes secundárias longas e as terciárias curtas com presença de nódulos; os cotilédones apresentavam coloração marrom, com presença de gemas e estípulas na base dos pecíolos e com presença de tricomas muito finos distribuidos por todo epicótilo de coloração vinho. O hipocótilo apresentou-se herbáceo longo, de coloração verde-escura com cotilédones de coloração marrom-escuro, de formato oblongo e textura carnosa. O epicótilo apresentou formato cilíndrico, de coloração verde-clara, piloso em toda a sua extensão. Constatou-se a presença de três a quatro pares de metáfilos bifoliolares, textura coriácea, coloração verde-escura na face superior (adaxial) e verde-clara na inferior (abaxial), pecíolo alado e glabro, provido de duas estípulas aciculares na base. Na referida espécie, até os 28 dias não constatou-se transição entre as primeiras folhas e as folhas posteriores, considerando-se nesse caso metáfilos (Figuras 7 e 8).

Todas as características descritas da espécie estudada mostraram-se relevantes para sua identificação, tanto em condições de casa de vegetação como em laboratório, corroborando com as pesquisas de Barretto e Ferreira (2011) e Botelho et al. (2000) quando ressaltam que os aspectos morfológicos de frutos, sementes, plântulas e mudas são essenciais não só para o reconhecimento das espécies em campo com também para estudos de recuperação de áreas degradadas, catalogação de espécies, estudos taxonômicos, possibilitando uma identificação

Cerne, Lavras, v. 18, n. 3, p. 353-360, jul./set. 2012 


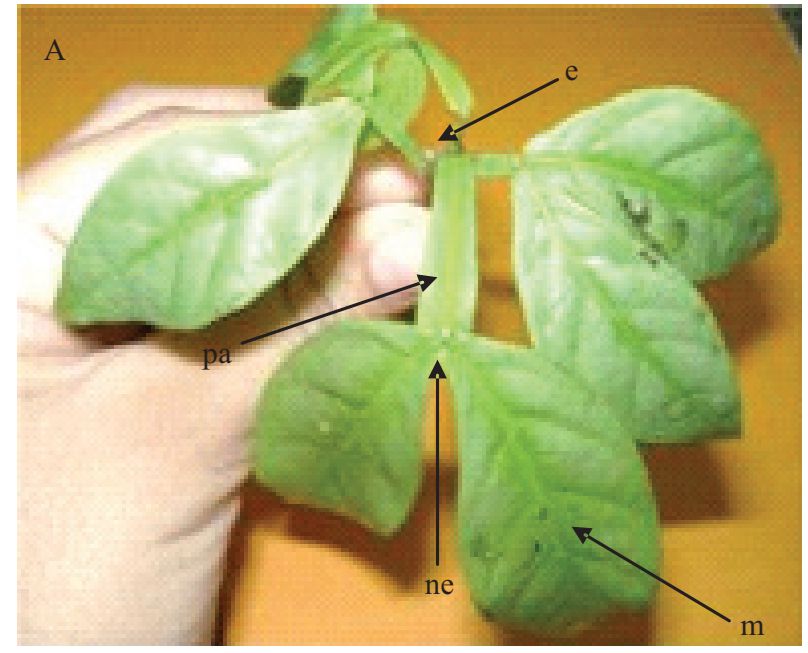

Figura 7 - Aspectos morfológicos do metáfilo de Inga ingoides (Rich) Willd.: A - m - metáfilo; e - estípula, pa - pecíolo alado, ne - nectários extraflorais.

Figure 7-Morphology of the metaphylls of Inga ingoides (Rich) Willd.: A - m - metaphylls, e - estipulas, pa - wings petiolar, nefloral nectarium.

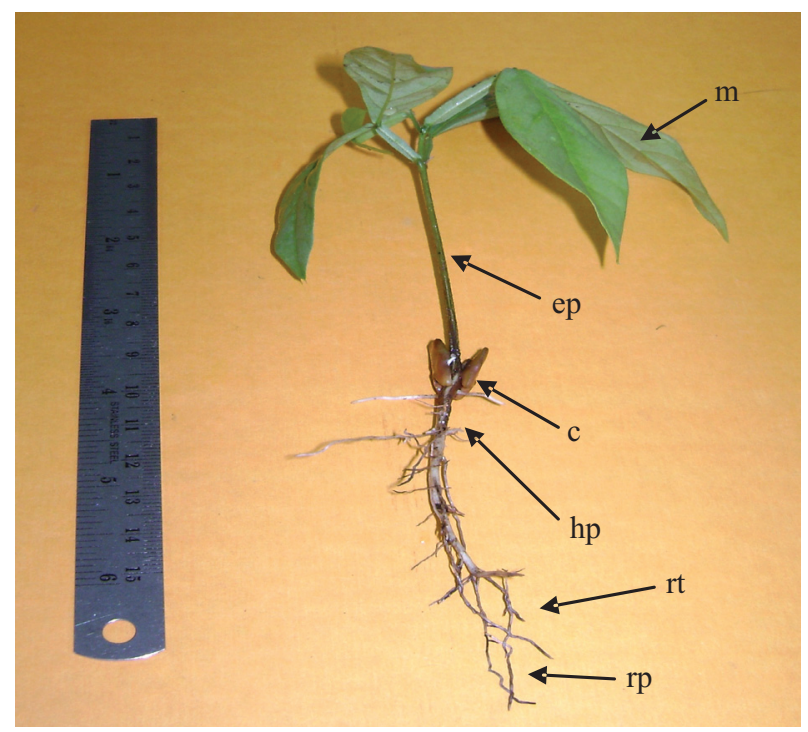

Figura 8 - Aspectos morfológicos externo da planta jovem de Inga ingoides Rich Willd aos 28 dias após a semeadura; rp - raiz primária, rs - raiz secundária, rt - raiz terciária, c - cotilédones, hp - hipocótilo, ep - epicótilo, m - metáfilo.

Figure 8 - Morphology aspect of Inga ingoides (Rich) sapling after 28 days of field: $r p$ - primary roots, $r s$ - secondary roots, $r t$ - terciary roots, $c$ - cotyledons, $h p$ - hipocotyl, ep - epicotyl, m-metaphylls.

Cerne, Lavras, v. 18, n. 3, p. 353-360, jul./set. 2012 imediata e segura no campo. Prosseguem os autores afirmando que, falta de pesquisas nesta área dificultam estudos relacionados à regeneração natural, às atividades silviculturais, e à preservação das espécies que correm risco de extinção.

\section{CONCLUSÕES}

O fruto de Inga ingoides (Rich) Willd., é do tipo legume, subtipo legume nucóide e apresenta 4 à 18 sementes por fruto. As sementes são de forma obvada, variando a oblonga com presença de sarcotesta. Apresentam germinação do tipo semi-hipógea, a plântula apresentou de imediato metáfilos bifoliolados de textura coriácea, coloração verde-escura na face superior (adaxial) e verde-clara na inferior (abaxial), pecíolo alado e glabro provido de duas estípulas aciculares na base, não apresentando transição entre as folhas aos 28 dias nas plantas jovens. As descrições da morfologia externa do fruto e da semente e as fases da germinação aliadas ás descrições das plantas jovens poderão servir de subsídios para identificação e diferenciação nos estágios iniciais do desenvolvimento das mesmas em condições de laboratório e de casa de vegetação.

\section{AGRADECIMENTOS}

As autoras agradecem à Dra Rita de Cássia Pereira curadora da Empresa Pernambucana de Pesquisa Agropecuária (IPA)-Herbário do Dárdano de Andrade Lima pela identificação da espécie.

\section{REFERÊNCIAS}

BARBEDO, C. J.; BILIA, D. A. C. Germinação de semente e desenvolvimento de plântulas de Inga uruguensis Hook e Arn. em função da remoção de sarcotesta. Informativo Abrates, Brasília, v. 7, n. 3, p. 379-391, 1997.

BARRETTO, S. S.; FERREIRA, R. A. Aspectos morfológicos de frutos, sementes, plântulas e mudas de Leguminosae Mimosoideae: Anadenanthera colubrina (Vellozo) Brenan e Enterolobium contortisiliquum (Vellozo) Morong. Revista Brasileira de Sementes, Brasília, v. 33, n. 2, p. 223-232, 2011.

BARROSO, G. M.; AMORIM, M. P.; PEIXOTO, A. L.; ICHASO, C. L. F. Frutos e sementes: morfologia aplicada à sistemática de dicotiledôneas. Viçosa, MG: UFV, 1999. 443 p. 
BELTRATI, C. M. Morfologia e anatomia de sementes. Rio Claro: UNESP, 1994. 109 p.

BETHAN, G. Legumoinosae II: swartzieae et caesalpinoideae. In: MARTIUS, C. F. (Ed.). Flora Brasiliensis. Lipsioe: Typografia Refie, 1976. p. 258-527.

BILIA, D. A. C.; BARBEDO, C. J.; CÍCERO, S. M.; MARCOS-FILHO, J. Ingá: uma espécie importante para recomposição vegetal em florestas ripárias, com sementes interessantes para a ciência. Informativo Abrates, Brasília, v. 13, p. 27-30, 2003.

BOTELHO, S. A.; FERREIRA, A. R.; MALAVASI, M. M.; DAVIDE, A. C. Aspectos morfológicos de frutos, sementes, plântulas e mudas de Jatobá-do- cerrado (Hymenaea stigonocarpa Mart. ex Hayne)- Fabaceae. Revista Brasileira de Sementes, Brasília, v. 22, n. 1, p. 144-152, 2000.

BRAVATO, M. Estudos morfológicos de frutos y semillas de lãs Mimosoideae (Leguminosae). Acta Botânica Venezuelica, Caracas, v. 9, n. 1, p. 317-361, 1974.

CARMONA, R.; REZENDE, L. P.; PARENTE, T. V. Extração química de sementes de gabiroba (Campomanesia adamantium Camb.). Revista Brasileira de Sementes, Brasília, v. 16, n. 1, p. 31-33, 1994.

COELHO, R. I.; LOPES, J. C.; GROTH, D.; SOUZA, N. A. Caractrização morfológica da planta, frutos, sementes e plântulas de tangerina (Citrus reticulata $\mathrm{L}$.) de ocorrência natural no sul do Estado do Espírito Santo. Revista Brasileira de Sementes, Brasília, v. 23, n. 2, p. 294-230, 2001.

CRONQUIST, A. The evolution and classification of flowering plants. New York: The New York Botanical Garden, 1988.

DAVIDE, A. C.; FERREIRA, R. A.; BOTELHO, S. A.; MALAVASI, M. M. Aspectos morfológicos de frutos, sementes, plântulas e mudas de candeinha (Eremanthus incanus Less.)-Asteraceae. Revista Brasileira de Sementes, Brasília, v. 22, n. 1, p. 127-133, 2000.

DUKE, J. A. Keys for the identification of seedling of some priminent woody species in weight forest types in Puerto Rico. Annals Missouri Botanical Garden, Saint Louis, v. 53, n. 3 , p. 314-350, 1965.
DUKE, J. A. On tropical trees seedlings I: seeds, seedlings, systems and systematics. Annals of the Missouri Botanical Garden, Saint Louis, v. 56, n. 2, p. 125-161, 1969.

DUKE, J. A.; POLHILL, R. M. Seedlings of Leguminosae. In: POLHILL, R. M.; RAVEN, P. H. (Ed.). Advancee in legume systematics. Kew: Royal Botanic Gardens, 1981. p. 941-949.

GUERRA, M. E. C.; MEDEIROS FILHO, S.; GALLÃO, P. M. I. Morfologia de sementes, de plântulas e da germinação de Copaifera langsdorffi Desf. (Leguminosae-Caesalpinoideae). Cerne, Lavras, v. 12, n. 4, p. 322-328, 2006.

JOLY, A. B. Botânica: introdução á taxonomia vegetal. 13. ed. São Paulo: Nacional, 2002.

LABOURIAU, L. G. A fisiologia de semente: germinação das sementes. Washington: OEA, 1983. 174 p.

MATA, M. F. O gênero Inga ( Leguminosoe, Mimosoideae) no Nordeste do Brasil: citogenética, taxonomia e tecnologia de sementes. 2009. 122 p. Tese (Doutorado em Agronomia) Universidade Federal da Paraíba, Areia, 2009.

OLIVEIRA, D. M. T. Morfologia comparada de plântulas e plantas jovens de leguminosas arbóreas nativas: especies de Phaseoleae, Sophoreae, Swartzieae e Tephrosieae. Revista Brasileira de Botânica, São Paulo, v. 24, n. 1, p. 85-97, jan./ fev. 2001.

OLIVEIRA, D. M. T.; BELTRATI, C. M. Morfologia e desenvolvimento das plântulas de Inga fagifolia e I. uruguensis. Turrialba, San José, v. 42, n. 3, p. 306313, 1992.

PARRA, G. P. Estudio de la morfologia externa de plântulas de Calliandra gracilis, Mimosa albida, Mimosa arenosa, Mimosa camporum, Mimosa tenuiflora. Revista da Faculdade de Agronomia, Uruguaiana, v. 9, n. 1/4, p. 311-350, 1984.

PENNINGTON, T. G. The genus Inga. Kew: Royal Botanic Gardens, 1997. 844 p.

PONCY, O. Graines, germination et plantules dans le genre Inga (Legumineuses, Mimosoideae): étude morphologique chez quelques espèces de Guyane française. Bulletin de La Societe d'Histoire Naturelle de Toulouse, Toulouse, v. 120, p. 35-42, 1984.

Cerne, Lavras, v. 18, n. 3, p. 353-360, jul./set. 2012 
SOUZA, L. A. de. Morfolologia e anatomia vegetal: célula, tecidos, órgãos e plântula. Ponta Grossa: UEPG, 2003. 259 p.
SOUZA, V. C.; LORENZI, H. Botânica sistemática: guia ilustrado para identificação das famílias de angiospermas da flora brasileira, baseado em APG II. Nova Odessa: Plantarum, 2005.

Cerne, Lavras, v. 18, n. 3, p. 353-360, jul./set. 2012 